\title{
THE ASSOCIATION BETWEEN BODY MASS INDEX AND DURATION OF SPINAL ANAESTHESIA IN ADULTS UNDERGOING TOTAL KNEE REPLACEMENT ARTHROPLASTY- AN OBSERVATIONAL STUDY
}

\author{
Sobha Sukumarapillai ${ }^{1}$, Haritha Indulekha² \\ ${ }^{1}$ Additional Professor, Department of Anaesthesiology, Government Medical College, Trivandrum. \\ ${ }^{2}$ Senior Resident, Department of Anaesthesiology, Government Medical College, Trivandrum.
}

\begin{abstract}
BACKGROUND

Total knee replacement is a surgical procedure in which parts of knee joint are replaced with artificial prosthesis so as to relieve pain and function of an arthritic knee. It is usually performed in geriatric patients under regional anaesthesia. In developing countries like India, majority of older population are overweight or obese according to standard body weight criteria. The aim of this study was to find out the association between body mass index and duration of spinal anaesthesia in adults undergoing total knee replacement arthroplasty.
\end{abstract}

\section{MATERIALS AND METHODS}

In this observational study, after obtaining institutional approval and individual consent, forty patients in the age group 40-80 years were randomly selected and were given combined spinal epidural anaesthesia. The primary objective was to find out the association between body mass index and duration of spinal anaesthesia in these patients. The secondary objectives were to find out the maximum block height, and duration of motor and sensory blockade in the study group.

\section{RESULTS}

In this study, it was found that patients with increased BMI attained maximum sensory level when compared to others with the same volume of drug. There is a strong positive correlation existing between body mass index and duration of anaesthesia as obese patients were found to have increased duration of both sensory and motor blockade.

\section{CONCLUSION}

From the present study, it was concluded that following spinal anaesthesia, the peak block height, the duration of sensory blockade and duration of motor blockade increase as BMI increases.

\section{KEYWORDS}

Total Knee Replacement Arthroplasty, Body Mass Index, Combined Spinal Epidural Anaesthesia.

HOW TO CITE THIS ARTICLE: Sukumarapillai S, Indulekha H. The association between body mass index and duration of spinal anaesthesia in adults undergoing total knee replacement arthroplasty- An observational study. J. Evolution Med. Dent. Sci. 2017;6(32):2665-2669, DOI: 10.14260/Jemds/2017/574

\section{BACKGROUND}

Total Knee replacement arthroplasty is the surgical treatment to relieve pain and function of an arthritic knee in which the parts of knee joint are replaced with artificial prosthesis. The geriatric population all over the world is on an increase. As a result the number of patients requiring TKR has also increased.

Total knee replacement is usually performed under spinal anaesthesia. It is a type of regional anaesthesia where the local anaesthetic is injected in to the subarachnoid space in order to obtain a sensory loss with or without motor blockade for any surgical procedure below the level of T4. In total knee replacement surgeries, a sensory level of T12 provides excellent anaesthesia for the patient. Spinal anaesthesia is advantageous in that it uses a small dose of the

Financial or Other, Competing Interest: None.

Submission 27-01-2017, Peer Review 08-04-2017,

Acceptance 14-04-2017, Published 20-04-2017.

Corresponding Author:

Dr. Sobha Sukumarapilla

Additional Professor,

Department of Anesthesiology,

Government Medical College,

Trivandrum.

E-mail: sobhathambu@yahoo.co.in

DOI: $10.14260 /$ jemds $/ 2017 / 574$ local anaesthetic, is simple to perform with rapid onset of action, reliable surgical analgesia and good muscle relaxation. ${ }^{1}$ These advantages are sometimes offset by a relatively short duration of action and patients experience pain especially in the postoperative period when the block wears off. In order to provide post-operative analgesia, combined spinal epidural anaesthesia can be provided as it may go a long way in alleviation of pain and suffering.

Currently, anilide compound bupivacaine is the most popular drug used for spinal anaesthesia. There are multiple factors affecting the level of spinal block in subjects undergoing spinal anaesthesia which include age, gender, height, weight, body mass index, spinal anatomy, CSF volume, etc. whereas factors affecting duration of spinal anaesthesia is not studied much in detail. ${ }^{2}$ However, factors affecting the level of spinal anaesthesia can also influence the duration as a higher level may cause prolonged duration of anaesthesia. Among these factors the influence of body mass index on spinal anaesthesia is controversial as previous studies on this have reported conflicting results. Obesity has been reported to be associated with greater cephalad spread of spinal anaesthesia. This may be due to decreased vertebral canal space or reduced CSF volume due to extradural vein distension or epidural fat. However, the study which found out this association used isobaric local anaesthetic which is associated with increased variability in block level. ${ }^{3}$ But a 
subsequent study using hyperbaric solution failed to show a significant increase in block height in obese individuals. ${ }^{4}$ Although the degree of cephalad spread may be unchanged, the possibility remains that anaesthetic duration which was not evaluated in these studies may be prolonged in obese patients.

In most developed and developing countries like India, majority of older people are overweight or obese according to standard body weight criteria. ${ }^{5}$ Increased Body mass index is proved to be an important cause of osteoarthritis in old age, which in turn is the most common indication for total knee replacement arthroplasty. Hence, it is worthwhile determining the association between body mass index and duration in these patients as prolonged spinal anaesthesia can cause discomfort, bladder dysfunction, etc.

Even though a similar study has been done in the west, 6 study on the above topic has not been done in our country where elderly population is on a rise. It is in this context that this particular study becomes relevant.

\section{MATERIALS AND METHODS}

After getting approval from ethical committee and individual informed consent the study was conducted. The study design was that of a prospective observational study involving 40 patients with American Society of Anesthesiologists Physical Status classification I to III. According the previous report, the correlation coefficient ( $\mathrm{r}$ ) for the relationship between BMI and duration of spinal blockade was $0.44 .{ }^{6}$ This information is used to calculate sample size for the present study. Sample size is calculated using the formula.

$$
\mathrm{N}=\frac{\left(\mathrm{z}_{1-\beta}+\mathrm{z}_{1-\frac{\alpha}{2}}\right)^{2}}{\frac{\mathrm{r}^{2}}{1-\mathrm{r}^{2}}}
$$

Where $z_{1-\frac{\alpha}{2}}=1.96$ (for significance 95\%), $z_{1-\beta}=0.84$ (for power $80 \%$ ) and $r=0.44$ (correlation coefficient from previous study). The calculated sample size from the equation was 33. However, it was decided to enrol 40 patients to compensate for dropouts.

The inclusion criteria were adults of age group 40 to 80 years with height and BMI in range of $130-180 \mathrm{~cm}$ and 18.5 - 45 respectively. Those patients with history of previous spinal surgery, skin infection at the site of injection, coagulation disorders and allergy to bupivacaine were excluded from the study. During the pre-anaesthetic checkup height and weight of each patient was taken and BMI was calculated. ${ }^{5}$

On the day of surgery after attaching electrocardiogram, pulse oximeter and blood pressure cuff baseline values were recorded. Normal saline @ $8 \mathrm{~mL} / \mathrm{kg}$ was given during the first 10 minutes and later by calculating the fluid need. A combined spinal epidural technique was performed with the patient in sitting position. An 18 G Tuohy needle was inserted at L2-L3 interspace with loss of resistance technique and an epidural catheter was threaded 4 to $5 \mathrm{~cm}$ in to the epidural space and aspiration for blood and CSF was done. Epidural test dose was given with $3 \mathrm{~mL}$ of Inj. Lignocaine $2 \%$ with 1:200,000 adrenaline. Spinal puncture was performed at L3L4 interspace using 23G Quincke spinal needle and $2.7 \mathrm{~mL}$ of hyperbaric $(0.5 \%)$ Bupivacaine was given. The needle orifice was placed cephalad during injection and all patients were placed in supine horizontal position after the procedure. Successful induction was defined as bilateral sensory block at or above T12 to pinprick within 15 minutes of intrathecal drug administration. ${ }^{7}$

Failed anaesthesia was defined as induction failure or an initial requirement of supplemental epidural analgesia with 2 $\%$ lignocaine with $1: 200,000$ adrenaline in $5 \mathrm{~mL}$ boluses repeated as required to complete surgery. Before starting the surgery tourniquet was applied over the thigh of the operating limb to decrease the blood loss during the surgery. The duration of spinal anaesthesia was obtained from time taken for two segment regression from the peak block sensory height. It was calculated in minutes.

The peak sensory level was recorded bilaterally along the midclavicular line by assessing changes in pinprick sensation using a 23 G needle. Sensory levels were assessed according to the following scale 8 :

- $0=$ an ability to appreciate a pinprick as sharp

- 1 =perception of a pinprick as less sharp as unblocked areas

- $2=$ perception of a pinprick as touch but not sharp (analgesia)

- $3=$ an inability to feel pinprick (anaesthesia)

Surgery was allowed to start when scale was $>$ or $=2$ assessed at or above T12. Sensory block assessments were performed 5, 10, 15 and thereafter every 15 minutes till two segment regression was achieved.

Motor blockade was assessed immediately after sensory block assessment using a Modified Bromage scale. ${ }^{9}$

- Modified Bromage scale 0 - no paralysis

- Modified Bromage scale 1- unable to raise extended leg

- Modified Bromage scale 2 - unable to flex knee

- Modified Bromage scale 3 - unable to flex ankle

Motor block duration was defined as time for return to Modified Bromage scale 1. It was calculated in minutes. Motor blockade was assessed every 5 minutes for first 15 minutes and thereafter every 15 minutes during surgery and postoperatively.

Vitals such as pulse rate, noninvasive blood pressure, oxygen saturation were recorded every 5 minutes in the initial 15 minutes and every 15 minutes thereafter. Hypotension was defined as decrease in systolic arterial pressure of greater than or equal to $20 \%$ relative to baseline or a mean arterial pressure of less than $55 \mathrm{mmHg}$. During hypotension IV ephedrine bolus doses of $5 \mathrm{mg}$ were administered. For heart rate less than 50 beats per minute, atropine $0.6 \mathrm{mg}$ IV was given. Epidural anaesthesia was initiated with Inj. Lignocaine 2\% with 1:200,000 adrenaline in boluses of $5 \mathrm{~mL}$ when the patient complained discomfort due to tourniquet application in the intraoperative period $\mathbf{1 0}$ or when the sensory level falls below L1 during the postoperative period.

The data obtained were entered in excel and analysed using Epi-info/SPSS 16.0 version software. All quantitative variables were expressed in mean and standard deviation. Qualitative variables were expressed in frequency and percentage. The correlation between BMI and duration of anaesthesia was derived using Pearson correlation and is expressed as correlation coefficient $r$. The association 
between BMI categories and duration of spinal anaesthesia was tested using ANOVA. For all statistical evaluation, a probability value $(\mathrm{p})<0.05$ was considered significant.

\section{RESULTS}

Out of 40 patients, $17.5 \%, 17.5 \%, 10.25 \%, 17.5 \%, 17.5 \%$ and $5 \%$ belonged to age group less than $60,61-65,66-70,71-75$, 75-80 and more than 80 respectively. The age ranged in between 49 and 82 in the study group with a mean of $68.5 \pm 7.4$.

$65 \%$ of the patients in the study group were female.

Out of the total study group, $12.5 \%$ had height in the range of $130-140 \mathrm{~cm}, 15 \%$ in the range $141-150 \mathrm{~cm}$. Maximum number of persons i.e. $40 \%$ had height in the range of $151-160 \mathrm{~cm} .20 \%$ had in the range $161-170 \mathrm{~cm}$ whereas $12.5 \%$ had in the range of $170-180 \mathrm{~cm}$. The height ranged in between $137 \mathrm{~cm}$ and $177 \mathrm{~cm}$ in the study group with a mean height of $156.7 \pm 10.8 \mathrm{~cm}$. In the study group, maximum number of patients (35\%) had weight in the range of $71-80 \mathrm{~kg}$. $25 \%$ had in the range of $60-70 \mathrm{~kg}, 22.5 \%$ in the range $81-90 \mathrm{~kg}, 12.5 \%$ in the range $91-100 \mathrm{~kg}$ and $5 \%$ had their weight above $100 \mathrm{~kg}$. The weight ranged in between 60 $\mathrm{kg}$ and $106 \mathrm{~kg}$ with a mean of $80.2 \pm 11.2 \mathrm{~kg}$ (Table 1). Out of the total study group, only $5 \%$ had normal BMI whereas $22.5 \%$ were overweight and $72.5 \%$ were obese (Table 2).

Maximum percentage of persons (32.5\%) attained peak sensory level of T8, followed by T9 $(27.5 \%)$ and T10 (20\%). $12.5 \%$ attained a level of $\mathrm{T} 7$ and $7.5 \%$ attained a level of $\mathrm{T} 6$. $2.5 \%$ attained a level of T 4 and $\mathrm{T} 5$. It was also found out that there is a strong positive correlation between BMI and peak sensory blockade as obese patients attained higher level (Fig. 1).

The duration of sensory block was $<60$ minutes for $12.5 \%$ of the study group. $40 \%$ had sensory duration in the range 61-100 minutes. $27.5 \%$ had in the range of $101-140$ minutes and $20 \%$ in the range of 141-180 minutes. The minimum duration of sensory block was found to be 45 minutes and maximum duration was 180 minutes with a mean value of 103.1 \pm 38.3 minutes. The mean duration of sensory block for persons with normal BMI was found to be $60 \pm 21.2$ minutes. For overweight persons, it was found to be $73.3 \pm 20.5$ minutes and for obese it was found to be $115.3 \pm 36.5$ minutes. Correlation between BMI and duration of sensory block was analysed by Pearson correlation, the correlation coefficient $r=0.815$ shows that there was strong positive correlation between BMI and duration of sensory block $(\mathrm{P}<0.001)$ Cases with high BMI had longer duration of sensory blockade (Table 3 ).

$15 \%$ had their duration of motor block in the range of 60 120 minutes. Maximum persons (55\%) had in the range of $121-180$ minutes. $30 \%$ had in the range of $181-240$ minutes. The minimum duration of motor blockade was found to be 60 minutes and maximum was 240 minutes with a mean value of $160.1 \pm 39.1$. It was found that mean duration of motor block in persons with normal BMI was $127.5 \pm 10.6$ minutes. For overweight persons, it was $121.7 \pm 24.2$ minutes and for obese individuals it was much prolonged with the value being $174.3 \pm 34.6$ minutes. Correlation between BMI and duration of motor block was analysed by Pearson correlation, the correlation coefficient $r=0.838$ shows that there was strong positive correlation between BMI and duration of motor block $(\mathrm{P}<0.001)$. Cases with higher BMI had longer duration of motor blockade (Table 4).

\begin{tabular}{|c|c|}
\hline Number of Patients & 40 \\
\hline Age in Years (Mean) & $68.5 \pm 7.4$ \\
\hline Height in cm (Mean) & $156.7 \pm 10.8$ \\
\hline Weight in Kg (Mean) & $80.2 \pm 11.2$ \\
\hline
\end{tabular}

Table 1. Demographic Data of Patients in the Study Group

\begin{tabular}{|c|c|c|}
\hline BMI & Frequency & Percent \\
\hline Normal & 2 & 5.0 \\
\hline Overweight & 9 & 22.5 \\
\hline Obese & 29 & 72.5 \\
\hline Total & $\mathbf{4 0}$ & $\mathbf{1 0 0 . 0}$ \\
\hline \multicolumn{2}{|c|}{ Table 2. Distribution of BMI in the Study Group } \\
\hline
\end{tabular}

\begin{tabular}{|c|c|c|c|c|c|}
\hline \multirow{2}{*}{ BMI } & \multirow{2}{*}{$\mathbf{N}$} & \multicolumn{2}{|c|}{ Duration of Sensory } & \multirow{2}{*}{ F } & \multirow{2}{*}{ P } \\
\cline { 3 - 4 } & & Mean & SD & & \\
\hline Normal & 2 & 60.0 & 21.2 & & \\
\hline Overweight & 9 & 73.3 & 20.5 & \multirow{2}{*}{7.202} & .002 \\
\hline Obese & 29 & 115.3 & 36.5 & & \\
\hline Total & $\mathbf{4 0}$ & $\mathbf{1 0 3 . 1}$ & $\mathbf{3 8 . 3}$ & & \\
\hline \multicolumn{7}{|l|}{ Table 3. BMI and Duration of Sensory Block } \\
\hline
\end{tabular}

\begin{tabular}{|c|c|c|}
\hline Correlation with BMI & r & P \\
\hline Duration of sensory & $0.815^{* *}$ & $<0.001$ \\
\hline
\end{tabular}

** Correlation between BMI and Duration of Sensory block was analysed by Pearson correlation, the correlation coefficient $r=0.815$ shows that there was strong positive correlation between BMI and duration of sensory block $(\mathrm{P}<0.001)$. Cases with higher BMI had longer duration of sensory blockage.

\begin{tabular}{|c|c|c|c|c|c|}
\hline \multirow{2}{*}{ BMI } & \multirow{2}{*}{$\mathbf{N}$} & \multicolumn{2}{|c|}{ Duration of Motor Block } & \multirow{2}{*}{$\mathbf{F}$} & \multirow{2}{*}{$\mathbf{P}$} \\
\hline & & Mean & SD & & \\
\hline Normal & 2 & 127.5 & 10.6 & \multirow{4}{*}{10.277} & \multirow{4}{*}{$<0.00$} \\
\hline Overweight & 9 & 121.7 & 24.2 & & \\
\hline Obese & 29 & 174.3 & 34.6 & & \\
\hline Total & 40 & 160.1 & 39.1 & & \\
\hline
\end{tabular}

\begin{tabular}{|c|c|c|}
\hline Correlation with BMI & R & P \\
\hline Duration of motor block & $0.838^{* *}$ & $<0.001$ \\
\hline
\end{tabular}

\footnotetext{
** Correlation between BMI and Duration of motor block was analysed by Pearson correlation, the correlation coefficient $r=0.838$ shows that there was strong positive correlation between BMI and duration of motor block $(\mathrm{P}<0.001)$. Cases with higher BMI had longer duration of motor blockage.
} 


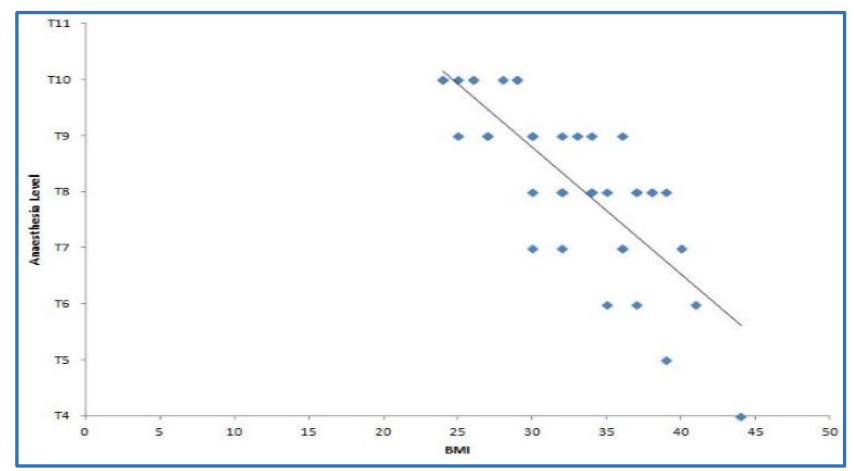

Figure 1. Correlation Between BMI and Peak Sensory Blockade

\section{DISCUSSION}

Total knee replacement arthroplasty is one of the most commonly performed orthopaedic procedure in the modern era, the main indication being osteoarthritis. Due to better healthcare facility, the life expectancy has increased all over the world and as a result the number of Total knee replacement arthroplasties being performed is on an increase. This is usually done under combined spinal epidural anaesthesia which is considered a better technique over general anaesthesia. Several studies have been done all over the world to find out the effect of body mass index on block height as well as duration of spinal anaesthesia. In this context association between body mass index and duration of spinal anaesthesia was studied.

In the study group, age ranged between 49 and 82 years with a mean age of $68.5 \pm 7.4$. From this it is concluded that incidence of knee replacement surgeries are more common in elderly population. A study done by Shane Anderson and Loeser R F also concluded the above fact. 11

In this study, majority of the patients were female (65\%) which implies arthroplasty procedures are more performed in women in our setting. A study on the epidemiology of total knee replacement in the south-east Asia by H Kim, S Kim ${ }^{12}$ showed similar results with rate of TKR in women being 8 times more than men.

The height ranged from $137 \mathrm{~cm}$ to $177 \mathrm{~cm}$ in the study group with a mean height of $156.7 \pm 10.8$ and weight ranged in between $60 \mathrm{~kg}$ and $106 \mathrm{~kg}$ with a mean of $80.2 \pm 11.2 \mathrm{~kg}$. Out of the total study group, only $5 \%$ had normal BMI (18-25) whereas $22.5 \%$ were overweight (26-29.9) and $72.5 \%$ were obese $(>30)$. This value brings out the fact that majority of the patients undergoing Total knee replacement arthroplasty were obese thus highlighting the relevance of this study. According to the study done by Kerkhoffs and colleagues, obesity is a well-documented risk factor for total knee arthroplasty. ${ }^{13}$

In the study it was found that patients with increased BMI had increased peak sensory level with the same volume of drug. A study by Hyo-Jin Kim and colleagues ${ }^{\mathbf{1 4}}$ also concluded that peak sensory block height increases in obese patients. The speculated reason for this is the decreased CSF volume in obese persons. A previous study using MRI15 demonstrated that CSF volume in obese patients is reduced. Although the mechanism of CSF volume reduction in obese patients has not been proved, possible explanations suggest that reduced CSF volume is a result of increased intra-abdominal pressure or increased epidural fat. ${ }^{16}$ If the inferior vena cava is occluded by increased abdominal pressure due to the weight of the abdominal contents in obese patients, blood flow increases through the lumbar vertebral plexus, and the extradural vein distends. Since a distended extradural vein is known to compress the CSF space, the volume of CSF is often reduced in obese patients, meaning that the spread of local anaesthetics can be increased. In support of this idea, a previous study using myelography ${ }^{17}$ demonstrated that abdominal compression increased the spread of radiopaque material in the CSF space. Thus, a greater cephalad spread of the sensory block level was achieved by increased intra-abdominal pressure. It is also theorised that the reduced CSF volume seen in obese patients may be due to increased extradural fat deposits, which could reduce CSF volume by compressing the dural sac. However, a previous study with endoscopic observation of the epidural space reported that the amount of epidural fat did not appear to be correlated with BMI.18

The minimum duration of sensory block was found to be 45 minutes and maximum duration was 180 minutes with a mean value of $103.1 \pm 38.3$ minutes. The mean duration of sensory block for persons with normal BMI was $60 \pm 21.2$ minutes. For overweight persons, it was $73.3 \pm 20.5$ minutes and for obese it was $115.3 \pm 36.5$ minutes. There was strong positive correlation between BMI and duration of sensory block as persons with high BMI had increased duration of sensory blockade. A study by Taner Ciftci and colleagues ${ }^{19}$ also had a similar finding. There are several postulations regarding increased duration of sensory blockade in patients with increased BMI, one being decreased CSF volume as already mentioned. If the same amount of bupivacaine is injected into a patient with a smaller CSF volume, the concentration of bupivacaine in the CSF would be higher, and a delayed regression of sensory block level would be expected. Also in spinal anaesthesia, the local anaesthetic, which is given at the subarachnoid space, is absorbed by the veins and is eliminated and diffused from the arachnoid/dural membranes.

The elimination of local anaesthetics is affected by tissue blood flow, where high blood flow increases the elimination of local anaesthetics. Because the flow of blood is much higher at the anterior aspect of the spinal cord, the elimination of local anaesthetics is faster. ${ }^{20}$ In our study, the low level of sensory in non-obese patients, when compared to obese patients, may have been caused by an increase in blood flow and a subsequent increase in arterial pressure in the spinal cord and the elimination of local anaesthetic.

Maximum persons (55\%) had their motor blockade in the range of 121-180 minutes. The minimum duration of motor blockade was 60 minutes and maximum was 240 minutes with a mean value of $160.1 \pm 39.1$. It was found that mean duration of motor block in persons with normal BMI was $127.5 \pm 10.6$ minutes. For overweight persons, it was $121.7 \pm$ 24.2 minutes and for obese individuals it was much prolonged with the value $174.3 \pm 34.6$ minutes. There was strong positive correlation between BMI and duration of motor block. Hence, it was concluded that cases with high BMI had longer duration of motor blockade, the reason being same as that of prolonged sensory blockade.

\section{CONCLUSION}

It was concluded that as BMI increases the duration of sensory and motor blockade increases along with increase in 
peak block height in patients undergoing total knee replacement following spinal anaesthesia.

\section{ACKNOWLEDGEMENT}

We wish to express our sincere gratitude to Dr. Usha Devi R. S., Professor and Head, Department of Anaesthesiology, Government Medical College, Thiruvananthapuram for her help and valuable opinion. We also wish to thank faculty and residents of Department of Anaesthesiology and Department of Orthopaedics for all the help and support.

\section{REFERENCES}

[1] Attari MA, Mirhosseini SA, Honarmand A, et al. Spinal anesthesia versus general anesthesia for elective lumbar spinal surgery - a randomized clinical trial. J Resp Med 2011;16(4):524-9.

[2] Sakura S. Factors influencing the level of spinal anesthesia: ll. Patient characteristics and technique of injection. Masui 2000;49(2):150-8.

[3] McCulloch WJ, Littlewood DG. Influence of obesity on spinal analgesia with isobaric $0.5 \%$ bupivacaine. $\mathrm{Br} J$ Anaesth 1986;58(6):610-4.

[4] Carvalho B, Collins J, Drover DR, et al. ED (50) and ED (95) of intrathecal bupivacaine in morbidly obese patients undergoing cesarean delivery. Anesthesiology 2011;114(3):529-35.

[5] Dalton WT, Wang L, Southerland JL, et al. Selfreported versus actual weight and height data contribute to different weight misperception classifications. South Med J 2014;107(6):348-55.

[6] Kim WH, Lee JH, Ko JS, et al. The effect of body mass index on spinal anesthesia for total knee replacement arthroplasty: a dose response study. Anaesth Intensive Care 2012;40(3):410-6.

[7] Capogna G, Celleno D, Laudano D, et al. Alkalinization of local anesthetics. Which block, which local anesthetic? Reg Anesth 1995;20(5):369-77.

[8] Ousely R, Egan C, Dowling K, et al. Assessment of block height for satisfactory spinal anesthesia for caesarean section. Anaesth 2012;67(12):1356-63.

[9] Bromage PR, Burfoot MF, Crowell DE, et al. Quality of epidural blockade. l. Influence of physical factors. Br J Anaesth 1964;36:342-52.
[10] Neal JM. Hypotension and bradycardia during spinal anesthesia: significance, prevention and treatment. Techniques in Regional Anesthesia and Pain Management 2000;4(4):148-54.

[11] Anderson SA, Loeser RF. Why is osteoarthritis an age related disease? Best Pract Res Clin Rheumatol 2010;24(1):15-26.

[12] Kim HA, Kim S, Seo YL, et al. The epidemiology of total knee replacement in South Korea: national registry data. Rheumatology (Oxford) 2008;47(1):88-91.

[13] Kerkhoffs GM, Servien E, Dunn W, et al. The influence of obesity on the complication rate and outcome of Total knee arthroplasty: a metaanalysis and systematic literature review. J Bone Joint Surg Am 2012;94(20):1839-44.

[14] Kim HJ, Kim WH, Lim HW, et al. Obesity is independently associated with spinal anesthesia outcomes: a prospective observational study. PloS One 2015;10(4):e0124264.

[15] Hogan QH, Prost R, Kulier A, et al. Magnetic Resonance imaging of cerebrospinal fluid volume and the influence of body habitus and abdominal pressure. Anesthesiology 1996;84(6):1341-9.

[16] Barclay DL, Renegar OJ, Nelson EW. The influence of inferior vena cava compression on the level of spinal anesthesia. Am J Obstet Gynecol 1968;101(6):792800.

[17] Taivainen T, Tuominen M, Rosenberg PH. Influence of obesity on the spread of spinal analgesia after injection of plain $0.5 \%$ bupivacaine at the L3-4 or L4-5 interspace. Br J Anaesth 1990;64(5):542-6.

[18] Blomberg R. The dorsomedian connective tissue band in the lumbar epidural space of humans: an anatomical study using epiduroscopy in autopsy cases. Anesth Analg 1986;65(7):747-52.

[19] Ciftci T, Kepekci AB, Yavasca HP, et al. The levels and duration of sensory and motor blockades of spinal anesthesia in obese patients that underwent urological operations in the lithotomy position. Biomed Res Int 2015;2015:5 Article ID 453939.

[20] Greene NM. Uptake and elimination of local anesthetics during spinal anesthesia. Anesthesia and Analgesia 1983;62(11):1013-24. 